\title{
Rol del cuerpo en Platón, una perspectiva foucaultiana
}

\section{Role of the body in Plato, a Foucaultian perspective}

\author{
García Zalazar, María Belén \\ Estudiante del Profesorado y Licenciatura en Filosofía \\ Universidad Nacional del Nordeste \\ belengarcia1692@gmail.com
}

\section{Resumen}

La investigación buscará realizar un análisis del papel del cuerpo en la noción Foucaultiana de Inquietud de sí en el período socrático platónico abordadas en la recopilación de clases titulada Hermenéutica del sujeto. En ella Foucault nos ofrece una nueva mirada sobre la concepción platónica de cuerpo y le otorgaría una función indispensable en lo referente al proceso de subjetivación entendida en el contexto de la relación del sujeto con la verdad.

Partiendo de la lectura del Fedro, diálogo platónico que relata lo referente al alma y a la caída de la misma del mundo de las ideas al plano sensible con la consecuente adopción de un cuerpo, se buscará señalar mediante los aportes foucaultianos, como ese cuerpo que representa la prisión a la cual se vio recluida el alma, se presenta a su vez como la condición de posibilidad de su liberación y retorno venturoso al plano eidético.

Palabras Clave: Inquietud de sí - Período socrático platónico - Alma - Plano Eidético Tecnologías del yo

\footnotetext{
Abstract

The research will seek to perform an analysis of the role of the body in Foucault's notion of restlessness in the Platonic Socratic period addressed in the collection of classes entitled Hermeneutics of the subject. In it, Foucault offers us a new look at the Platonic conception of the body and gives it an indispensable function
} 
in relation to the process of subjectivation understood in the context of the relation of the subject with the truth.

Starting from the reading of the Phaedrus, a Platonic dialogue that relates to the soul and its fall from the world of ideas to the sensible plane with the consequent adoption of a body, it will be sought to point out through Foucauldian contributions, like that body that represents the prison to which the soul was secluded presents itself in turn as the condition of possibility of its liberation and successful return to the eidetic plane.

Key Words: Self-concern - Platonic Socratic Period - Soul - Eidetic Plane - Ego Technologies

\section{Introducción}

Este tema se inserta en el marco de la investigación de la noción de sujeto foucaultiana perteneciente a un proyecto de beca y adscripción a la cátedra de Filosofía Antigua en curso, para el cual resulta de interés y utilidad profundizar en el rol que Platón le asigna al cuerpo en el proceso de subjetivación.

Cabe señalar, que el tema referente a esta investigación, si bien se halla disperso en varias obras foucaultianas que analizan el período socrático platónico desde la noción de inquietud de sí, no se encuentra precisado, dado que desempeña un rol secundario en el marco de la investigación siendo estos aportes y lecturas una novedad en la forma de entender la relación del cuerpo y alma en Platón.

El objetivo general de esta investigación, refiere a señalar la posibilidad de señalar una función positiva respecto a la idea de cuerpo platónica que resulta de importancia para llevar a cabo el mandato de la inquietud de sí durante el período socrático platónico. Esta función rescatada por Foucault en el análisis de este período clásico expuesto en su Hermenéutica del Sujeto, no habría sido contemplada antes, relegándole hasta el momento, solo una función carcelaria a la forma en la cual era comprendida la corporalidad platónica.

Para cumplir con dicho objetivo, se dispusieron una serie de objetivos específicos que al mismo tiempo cumplen las veces de metas intermedias en el proceso de aseveración de la hipótesis, ya que ayudan y llevan a ella, los mismos son: 
en primer lugar, analizar a partir de los aportes de la mirada foucaultiana la noción de cuerpo platónica, para luego, determinar el rol que desempeña la corporalidad para la Inquietud de Sí en el período socrático platónico; y, por último, establecer relaciones entre el papel desempeñado por el cuerpo en el proceso de subjetivación y su ascensión al mundo de las ideas platónico.

La metodología a seguir se basa en un proceso interpretativo guiado por el análisis crítico-comparativo de los textos seleccionados, atendiendo a la elucidación de sus principales supuestos y consecuencias y a la reconstrucción de sus argumentos centrales. El método a seguir es del orden analítico crítico-comparativo, y las técnicas refieren al análisis, comprensión y comparación explicativa de los temas abordados, la lectura compresiva y análisis de las obras, la reconstrucción de los presupuestos más importantes y evaluación de las consecuencias derivadas de su uso, y la interpretación de los sentidos de los textos a la luz del contexto de su producción, así como su consecuente relación con otros textos y fuentes.

El trabajo consta de tres apartados, en el primero, se realiza una breve exposición de la concepción tradicional del cuerpo platónico, en la segunda, una exposición de la teoría foucaultiana de la Inquietud de sí, de la cual se recatarán los aportes relacionados a una visión positiva respecto al cuerpo platónico que serán desarrolladas en el tercer apartado. Los autores citados en el primer apartado, tomarán como base de su teoría los diálogos medios de Fedón y Fedro, a diferencia de Foucault que para su estudio se basa en los diálogos tempranos de la Apología de Sócrates y Alcibíades, el análisis de los mismos nos permite leer en un contexto diferente a los diálogos posteriores que siempre sentaron las bases del dualismo antropológico platónico.

\section{Cuerpo como cárcel del alma}

Lo referente al título de este apartado, hace a la concepción tradicional del cuerpo platónico, la cual se hallaba identificado con atributos negativos como tumba o cárcel del alma. Esta visión peyorativa, no fue dada adrede, sino que encuentra su base en diversos diálogos platónicos entre los que destacan los diálogos medios de Fedro y Fedón, ya que es en ellos que se da un desarrollo significativo respecto al tema y nos permite armar las piezas que serán luego usadas por diversos filósofos en 
sus respectivas obras. Al hablar de la concepción antropológica platónica, no solo la categorizan de dualista, sino que además estas dos partes que lo componen, como lo son el cuerpo y el alma, no solo son diferentes, sino que, además se encuentran opuestas y en conflicto.

Dado que el cuerpo representa una cárcel para el alma que solo anhela volver a contemplar las ideas en el plano inteligible, aparece como la fuente de todos los males y desgracias para el hombre, es la representación de todo lo viciado. Lejos de poderle sacar algún provecho, el sabio, que busca vivir conforme a las Ideas, constantemente huye y reniega de él, prefiriendo incluso la muerte bienaventurada que lo librará por fin de las garras de aquello que pudiera viciar su alma y alejarla de la tan preciada virtud.

Giovanni Reale (1988) en su primer tomo de Historia de la Filosofía, considerado como un manual ${ }^{1}$ base en filosofía, refiere a la concepción antropológica platónica como dualista donde la relación entre el cuerpo y el alma se desarrolla de manera contrapuesta, esta oposición en algunos diálogos platónicos llega a presentarse en sentido total y radical, en la cual el cuerpo es para el alma una tumba, una cárcel y un lugar de expiación (p. 142). Nada bueno le es atribuido al cuerpo, y esta idea se encuentra a reforzada por el autor cuando afirma que "el cuerpo es la raíz de todo mal, es origen de los amores alocados, pasiones enemistades, discordias, ignorancia y demencia... todo esto en lo que lleva a la muerte al alma" (p. 143), aunque es solo el cuerpo el que perece en sentido ontológico. Es el cuerpo quien limita y enturbia al alma, obstaculizando su camino de perfeccionamiento y la priva de la contemplación de las ideas con quienes el alma comparte naturaleza ya que ambas pertenecen al plano suprasensible. También se configura como un lugar de expiación, una cárcel de la cual solo puede liberarse con ayuda de la filosofía, que es quien la conduce de nuevo a la virtud y el conocimiento que le son propios.

Todo esto, tiene su punto de partida Platón que se expresa de la siguiente manera respecto a las diferencias entre la naturaleza del cuerpo y del alma:

\footnotetext{
${ }^{1}$ Siendo mencionado Reale entre otros que igualmente podrían ser citados, como lo son Fraile, Copleston, Rodolfo Mondolfo, etc.
} 
El alma es lo más semejante a lo divino, inmortal, inteligible, uniforme, indisoluble y que está siempre idéntico consigo mismo, mientras que, a su vez, el cuerpo es lo más semejante a lo humano, mortal, multiforme, irracional, soluble y que nunca está idéntico a sí mismo (...), le conviene al cuerpo disolverse pronto, y al alma, en cambio, ser por completo indisoluble o muy próxima a ello. (Fedón 80b1-11)

En este pasaje, se expresa no solo su diferencia ontológica, sino también su oposición esencial. El alma se presenta como lo divino, y comparte sus cualidades y notas esenciales, es inmortal, por lo cual preexiste a su vida corporal y subsiste también a la misma; el cuerpo resulta un desafortunado accidente en medio de esta línea temporal, del cual solo sería posible liberarse, en primera instancia y de manera parcial, por medio de la práctica filosófica, y luego de manera definitiva, con la muerte corporal.

Pero primero, para entender la razón del infortunio, "Es necesario ante todo comprender la verdad sobre la naturaleza del alma, tanto divina como humana, prestando atención a sus afecciones y operaciones" (Fedro 245 c4-7), es por ello que, para abordar con mayor profundidad, la composición particular que tiene el alma en Platón, recurriremos al Mito del Carro Alado ${ }^{2}$ relatado en el diálogo del Fedro que, por razones de extensión del trabajo, se eligió en lugar de realizar citas, relatar el mismo en breves palabras. Su mención no podía resultar exenta, dado que la misma, reviste de importancia para explicar más adelante aspectos que hacen referencia a la concreción de los objetivos propuestos para esta investigación.

Con este relato mítico de estilo alegórico tan característico de Platón, el autor nos ofrece una explicación de la naturaleza y composición del alma. Para explicarla recurre a la imagen de un carro alado conducido por un auriga y tirado por dos caballos, uno negro y otro blanco; que junto a los dioses participa de la caravana de almas que busca contemplar el mundo de las ideas. Cada personaje del carro, representa una parte del alma, para Platón, tripartita. El auriga, simboliza a la razón (logistike) y busca contemplar las Ideas, el caballo blanco o parte irascible

\footnotetext{
${ }^{2}$ Cabe señalar que, este no es el único de sus diálogos en el que Platón expone su teoría respecto al alma tripartita, sino que también lo hace en la República, en la cual establece una relación analógica entre la misma y el Estado.
} 
(thymoeides), simboliza la fuerza y valentía, y el caballo negro, la parte apetitiva y concupiscible del alma (epithymetike), que busca satisfacer sus apetitos, pero para ello precisa de un cuerpo y esta es la razón por la cual constantemente busca precipitarse al mundo sensible, oponiendo constante resistencia al auriga. Si el caballo negro logra aliarse con el caballo blanco, el alma se precipita al plano sensible y posee un cuerpo.

Cae el alma así, en su mayor desgracia e infortunio, ya que se ve privada del deleite de contemplar resplandecientes a las ideas y de participar del beatífico espectáculo de la caravana de almas que los dioses encabezasen, "contemplábamos un resplandor puro, puros nosotros también y sin señal de ese sepulcro que ahora llamamos cuerpo, y al que llevamos a nuestro alrededor, prisioneros cual ostras". (Fedro 250c6-9)

El tiempo que pase el alma en el mundo sensible, así como el número de reencarnaciones y su lugar en la caravana de almas al volver al plano inteligible, dependen en gran medida de la vida que lleve el alma en su tránsito por el mundo sensible, según se halla conducido bien y haya logrado recordar las Ideas contempladas anteriormente, esto refiere al hecho de haberse dedicado a la filosofía, ya que es la dialéctica la que le permitiría esa reminiscencia tan preciada.

El alma de un (...) filósofo haría el razonamiento siguiente, (...) era preciso que la filosofía la liberara, y, al liberarla, ella (no) debía entregarse a los placeres, y, a la vez a los dolores, encadenándose a sí misma de nuevo (...) Antes bien (...) obedeciendo al razonamiento y estando siempre de acuerdo con él, observando lo verdadero, lo divino y lo incuestionable, cree que debe vivir así mientras viva, y una vez que muera (...) quedará apartada de los males humanos (...) disgregada en la separación del cuerpo, se esfuma disipada por los vientos y revoloteando y no existe más en ninguna parte. (Fedón 84a2-b8)

Con este pasaje, Platón deja bien en claro cuatro puntos muy importantes, el primero, es que el alma del filósofo es un tipo de alma particular, porque en ella prima la razón por sobre los apetitos, en los cuales no está dispuesta a recaer luego de haber sido rehabilitada, la segunda, es que la independencia del alma por el acceso a lo verdadero e incuestionable se ve mediada por la filosofía, la cual representa el camino seguro, la tercera, es que el vivir según la razón le asegura al alma que al morir se vea 
alejada de los males humanos, y por último, que si su conducta hubiese correspondido perfectamente con la virtud en su vida corpórea, ya no tendría que volver a reencarnarse ni a experimentar los males de la propensión corporal concupiscible, o al menos, encontrarse más cerca de ese beatífico propósito.

Nada de lo que procede del cuerpo puede ser considerado bueno, y hay que desconfiar y apartarse de todo ello, incluso de los sentidos de los cuales nos provee y que consideramos propios, el alma solo puede captar lo puro y verdadero por sí misma, pero para eso debe hallarse purificada ella misma, porque a lo impuro no le es lícito captar lo puro, "el alma cuando utiliza al cuerpo para observar algo (...), es arrastrada por el cuerpo a cosas que no son idénticas, y ella se extravía, se perturba y se marea como si sufriera vértigo". (Fedón 79 c2-9)

Solo la muerte puede asegurarnos el verdadero acceso a la verdad, por más vida moderada y en todo correspondiente con la virtud que lleve, el alma solo se encuentra en el umbral del saber, a un paso del mismo, pero sin poder avanzar hacia él. Solo la muerte permite dar ese paso hacia la divinidad misma que nos libera. Es preciso purificar el alma y liberarse del cuerpo que estorba, para conocer y vivir acompañado por nosotros todo lo puro y verdadero, alcanzando al fin, la sabiduría anhelada, "y ese empeño es característico de los filósofos (...) la separación del alma del cuerpo". (Fedón d6-8), y es que la purificación es justamente esto, "la separación al máximo el alma del cuerpo y el acostumbrarse ella (el alma) a recogerse y concentrarse en sí misma fuera del cuerpo (...) liberada como de unas cadenas". (Fedón 67 c7-d2)

Es importante precisar en este contexto, que a pesar de la función liberadora de la muerte del alma respecto del cuerpo, con este argumento no fue la pretensión de Platón propugnar el suicidio, sino más bien, como él mismo lo expresa, el estar preparados para la muerte, y en el caso de estarlo y que esta llegase, estar advertidos de su benéfica función, siempre sin apresurarla, ya que el tiempo que demore resulta valioso para lograr un mayor perfeccionamiento y que ésta resulte aún más venturosa.

\section{Inquietud de Sí, una nueva perspectiva}

Las investigaciones del filósofo contemporáneo, Michel Foucault, expuestas en los cursos dictados en el College d'France de los años 80 que versan sobre la relación 
entre sujeto - verdad como proceso de subjetivación en la antigüedad, hacen un recorrido histórico, teniendo como hilo conductor el concepto foucaultiano de Inquietud de sí.

La noción de Inquietud de sí va tomando características diferentes en cada período histórico, que se distancian ampliamente de la Epimeleia Socrático platónica, como un nombre va cambiando de rostro con el pasar del tiempo, de igual modo, la Inquietud de sí no permanece inmutable ante el devenir histórico, y lo que una vez se asoció casi basalmente con la política y la pedagogía, se halló luego, en el período siguiente totalmente separada de ellas, para enraizarse en prácticas de vida.

No podemos decir que el término no sea anterior a Sócrates, pero es a partir de él que toma un sentido muy particular que es el que nos interesa aquí analizar. Este término griego representa el punto de partida para el desarrollo del presente trabajo, término que puede traducirse como inquietud de sí, preocupación de sí, ocuparse de sí y cuidado de sí. Ya en la Apología de Sócrates de Platón, en su discurso ante el tribunal, Sócrates mismo se presenta como aquel que incita a los otros a cuidar de sí mismos, es decir, de su alma; y es por eso que, a su parecer, él desempeña la tarea más importante en la ciudad y por ello no merece más que bienes a cambio del gran bien del que provee a sus conciudadanos. Más aún, y éste es un punto muy importante, esta labor tan loable que desempeña, no proviene de una decisión individual y voluntaria, sino que es designio de los dioses, como bien lo explicita en ese texto.

Otro aspecto a destacar, es el estrecho vínculo que guarda la Inquietud de sí con la Espiritualidad. La cual es definida por Foucault (2015), como: "el conjunto de búsquedas prácticas y experiencias... las modificaciones de la existencia, que constituyen no para el conocimiento sino para el sujeto, el precio a pagar por tener acceso a la verdad" (p.33). Es justamente esta espiritualidad, la que hace aparecer las técnicas de sí que son necesarias para la transformación del sujeto, ya que, sin dicha transformación, no habría acceso a la verdad. No se puede acceder a ella por el mero conocimiento de sí, o al menos este es el argumento sostenido en este momento, diferente a lo que luego se pensará, cuando se deje de lado la inquietud de sí.

Es desde ésta última afirmación también que podemos entender aquello que más adelante señala Foucault, que es la predominancia del Gnothi Seauton sobre 
la Epimeleia Heautou, durante tanto tiempo, y la razón por la cual, si bien sobrevivió y mutó durante el cristianismo primitivo, luego se vio opacada con el predominio de la razón del, por él denominado momento cartesiano, ya que el conocimiento de sí adquiere una importancia creciente como primera etapa en la teoría del conocimiento, y se vuelve el único requisito necesario para el acceso a la verdad, dejando ya de lado las tecnologías de sí. Durante la antigüedad, la cuestión filosófica del acceso a la verdad y la espiritualidad, se encuentran estrechamente ligadas, presentándose la Epimeleia Heautou como el conjunto de las condiciones de espiritualidad, de las transformaciones de sí, que son condición necesaria para que se pueda tener acceso a la sabiduría.

"Conócete a ti mismo", éste es uno de los preceptos que se halla en los dinteles del Templo de Delfos y que ha sufrido diversas apropiaciones que mucho distaban de la apreciación platónico- socrática de autoconocimiento. En el Diálogo del Alcibíades encontramos este término tres veces, haciendo referencia a tres aspectos diferentes de lo que significa el Gnothi Seauton en el sentido socrático- platónico. La primera como un consejo de prudencia, más parecido a las anteriores interpretaciones del precepto délfico, la segunda, como una cuestión metodológica al exhortar al joven a ocuparse de sí; y la tercera, refiriéndose al autoconocimiento que lleva a ese ocuparse de sí. Es justamente, ésta última la referencia, la que nos interesa de forma particular y a la que haremos referencia al usar el este término, y también la que como veremos más adelante, organiza las tecnologías de sí.

Podemos señalar dos sentidos del Gnothi Seauton: el primer sentido: es débil, como incitación a conocer capacidades debilidades (Apología de Sócrates); el segundo, en tanto sujeto-objeto de la Inquietud de sí, la psykhes o el alma (Alcibíades). En el período socrático-platónico se hallan enraizados en la idea de reminiscencia. El alma por medio del conocimiento de sí podría recordar la verdad contemplada en el mundo de las ideas.

Respecto a la relación entre conocimiento de sí y el cuidado de sí, señala Foucault que, a lo largo de la historia de la filosofía, se produce una inversión jerárquica entre los dos principios de la Antigüedad: el preocuparse de sí mismo y el conocimiento de sí mismo, en donde vemos primeramente que éste segundo se 
presentaba como consecuencia del primero, diferente de la tendencia moderna que llega a nuestra época, donde el conocimiento de sí, constituye el principio fundamental que opaca u obscurece a la preocupación de sí. Para diferenciar y conceptualizar mejor la inquietud de sí del conocimiento de sí, nos sirve caracterizar a cada uno, junto con sus implicancias mutuas y en qué consisten las tecnologías del yo, así como el rol que desempeñan. Foucault (2015) las define de la siguiente manera:

Conjunto de prácticas reflexivas y voluntarias mediante las cuales los hombres no solo se fijan reglas de conducta, sino que buscan transformarse, modificarse en su ser singular y hacer de su vida una obra que exprese ciertos valores estéticos y responda a algunos criterios de estilo. (p. 166)

Es decir, que pueden definirse como técnicas de transformación del Alma a sí misma, las cuales, en un primer momento se hallaban desligadas del factor conocimiento para ahora con Sócrates hallarse ligadas a este. Es el alma quien se preocupa por ella misma, y se ocupa de sí misma, y para saber de qué debe ocuparse, primero se conoce a sí misma.

En el momento socrático-platónico, las tecnologías de sí se hallan subordinadas al conocimiento de sí, dado que es éste el que las ordena y es el alma la que por medio de ese conocimiento y valiéndose del cuerpo, por medio de esas técnicas, se transforma. Es en este punto donde vemos aparecer como figura de importancia al cuerpo, ya que se muestra no como cárcel del alma, sino como instrumento, es decir, como condición de posibilidad del alma de valerse del cuerpo para vincularse y transformarse a ella misma en cuanto sujeto que busca acceder a la verdad.

Las tecnologías de sí, tienen una vida muy anterior a Platón, y ya se hallaban relacionadas con el saber, es decir, como condición necesaria para el acceso a la verdad. Entre ellos podemos destacar en la Grecia Arcaica, los ritos de purificación (para tener acceso a los dioses, que son quienes revelan la verdad), las técnicas de concentración del alma (de recogimiento en sí), la técnica de retirada o anakhoresis (cortar el contacto con el mundo exterior) y la práctica de resistencia (que permite soportar las pruebas más dolorosas). Ya durante los siglos I y II, hallamos todavía vestigios del pitagorismo, como son; la preparación purificadora para el sueño, 
que permitía entrar en contacto con el mundo divino y comprender sus significaciones, y las técnicas de prueba, que permitía someterse a una tentación y superarla.

A través de las imágenes de la Inquietud de Sí, nos acercamos a la Noción de conversión, una de las Tecnologías del Yo más importantes que conoció Occidente, la cual podemos traducir tanto como epistrephein pros heauton: volverse a sí mismo, convertirse a sí, y que durante el periodo que estamos analizando, porta características que le son particulares y exclusivas, como ser la oposición fundamental entre este mundo y el otro, la liberación o desprendimiento del alma con respecto del cuerpo, y el privilegio de conocer la verdad a través del acto de la reminiscencia.

Esta práctica espiritual, consta de tres momentos en su desarrollo, los cuales se dan de manera consecutiva. El primer momento, consiste en apartarse de las apariencias, es decir, de las cosas perecederas, hasta que se sea capaz de soportar la visión del Ser y de su parte más brillante que llamamos bien, este momento porta importancia ontológica. En la segunda etapa, avanzamos al retorno a sí, donde se constata la propia ignorancia y se reconoce la importancia de ocuparse de sí; para luego sí avanzar a la última fase, denominada como reminiscencia, que refiere a un volver a la patria ontológica de las esencias, la verdad y el ser.

La primera vez que hallamos la Epimeleia Heautou relacionada con el ejercicio de la política es en el diálogo platónico del Alcibíades, cuando Sócrates incita al joven Alcibíades a ocuparse de sí mismo si quiere ser un buen gobernante, aclarándole que, al ser aún joven, todavía tiene tiempo para ello. Aclaración que parece extraña, dado que, en su Apología, es también Sócrates quién exhorta a todos sin importar la edad a que cuiden de sí mismos, y allí no parece ser un requisito indispensable la edad. Éste punto es también advertido por Foucault.

Podría pensarse en un primer momento que la Apología de Sócrates y el Alcibíades se contradicen en cuanto al momento en el cual se debe dar la Epimeleia Heautou, pero también podemos llegar a otra interpretación, ya que en el caso de Alcibíades, la Inquietud de sí tenía un propósito bastante importante que trascendía el gobierno de sí a una tarea aún mayor, que es el gobierno de otros, desde ese punto, puede entenderse porqué se precisaba de que fuese aún joven para ello, ya que implica un esfuerzo mayor y por ende, un proceso más largo; en el caso del resto de los 
ciudadanos que no podían desenvolverse en la política (que no poseían el privilegio estatuario), dado que no reunían los requisitos necesarios, como el pertenecer a una casta noble o contar con la edad adecuada, la tarea de Sócrates o quien desempeñase el papel del maestro (es decir de quien los exhorta y acompaña en el proceso de conocimiento de sí), se vería acotada a lograr que se ocupen de sí mismos, y que puedan gobernarse bien, sin pasar necesariamente al gobierno de la ciudad.

La Inquietud de sí es la que permite al alma que alcance la sabiduría ${ }^{3}$ y con ella el conocimiento de lo bueno y lo malo, así como sujeto de acción, sabrá obrar correctamente, y al saberlo, eso es lo que elegirá ${ }^{4}$, y al comportarse como corresponde, sabrá cómo y podrá gobernar la ciudad.

El maestro tiene un papel muy importante en el proceso de conocimiento de sí, el mismo es desarrollado en el diálogo platónico del Alcibíades, en lo que se conoce como la metáfora del ojo. La misma, explica que el alma solo puede verse reflejada en una superficie de la misma naturaleza, como si se tratase de un espejo. Y cuanto más divina sea la superficie, mejor se verá el alma, por ello el más puro, claro y luminoso de los espejos es el dios. Así aparece como requisito del conocimiento, del saber, lo divino. Hay que conocer lo divino para conocernos a nosotros mismos.

En el caso de Sócrates su superficie de reflexión sería su daimon, y para Alcibíades, sería su maestro, Sócrates. Ésta sería justamente la tarea del maestro, ser esa superficie que devuelve el reflejo de sí al mancebo, y que lo ayuda en el camino de su conocimiento de sí.

"La intención inicial de Platón es política: cree en la posibilidad de cambiar la vida política por medio de la educación filosófica de los hombres que son influyentes en la ciudad" (Hadot, 1998. P. 70-71). Por lo dicho hasta aquí, podemos ver la importancia y conexión existente entre la Epimeleia Socrático-Platónica, con la política y la pedagogía. Conexión que no encontrará continuidad en los períodos posteriores y que se halla caracterizada de la siguiente manera: respecto de la pedagogía, la práctica de sí aparece como complemento o sustituto, dado que, aparece como un precepto que

\footnotetext{
${ }^{3}$ Sophrosyne = sabiduría

${ }^{4}$ Para Sócrates, conocer el bien, era equivalente a obrar bien, ya que consideraba que la única razón para obrar mal del hombre era la ignorancia, al conocer el bien, necesariamente lo elegiría. Conocer el Bien, en Platón, sería el primer paso para poder elegirlo.
} 
se impone al joven para entrar en la vida política adulta. Respecto de la política, se trata de velar sobre sí para poder ocuparse como corresponde de los otros y la ciudad.

\section{Redención del cuerpo platónico}

El alma es juzgada en el Hades con base en el único criterio de la justicia y la injusticia, de la templanza y el libertinaje, de la virtud y del vicio. Los juicios del más allá no se preocupan de otra cosa. No se tiene en cuenta para nada el que se trate del alma del Gran Rey o del más humilde de sus súbditos: solo se tiene en cuenta las señales de justicia o injusticia que lleve en sí misma. (Reale,1988, p. 149)

Cada uno de estos criterios de juicio, son susceptibles de juzgar el alma, más que el cuerpo. Hemos visto ya, en el Mito del Carro Alado, que el alma tiene una composición tripartita, y cada parte de la misma tiene sus características propias y bien diferenciadas entre sí, es así que, al auriga, o parte racional, le atrae la contemplación de las Ideas y el recto obrar, en oposición al caballo negro o parte apetitiva que solo desea precipitarse al mundo sensible para poseer un cuerpo y poder satisfacer sus apetitos desordenados; ambos serían los dos extremos entre los que se juega la suerte y el destino del hombre. La tercera parte del alma, identificada como el caballo blanco o la parte irascible, representa la fuerza del alma, según escuche al auriga o al caballo negro va escribiendo la suerte que le espera, no es bueno ni malo en sí mismo, es susceptible de ser usado para realizar el bien o el mal, y en este punto se identificaría con la función misma que desempeña el cuerpo en el mundo sensible, al ser posibilidad de que el alma se perfeccione y ascienda en cuanto al conocimiento y su consecuente lugar en la caravana de almas, así como puede hacer que descienda de lugar y ocupe lugares más desafortunados en las siguientes reencarnaciones.

El cuerpo en sí mismo, no es bueno ni malo, es el alma quien posee y comanda al cuerpo, y el mismo solo se presenta como una condición de posibilidad para la misma, que según sea accionado será una suerte afortunada o desafortunada, en consonancia con lo que es bueno o no. Es el alma la que, escindida en su esencia misma, se halla en constante lucha y contradicción con ella misma, ya que desea, por 
una parte, retornar a la patria de las Ideas, y, por otra parte, entregarse a la satisfacción de los placeres.

Para poder corregirse a sí misma, el alma cuenta con las tecnologías del Yo descriptas anteriormente en palabras de Foucault, y que son parte esencial para el cuidado de sí, ya que, ponen una llamada de atención sobre las prácticas que el alma realiza para transformarse a sí misma y tener acceso a la verdad, para obrar conforme a ella. El punto en común de éstas prácticas es que son acciones que, si bien se hallan motivadas o dirigidas por el alma, quien las realiza es el cuerpo, el alma necesita valerse del cuerpo para poder modificarse y purificarse. Es de aquí que podemos inferir que aquello que necesita purificarse en realidad es el alma misma, no el cuerpo, y que la tendencia tanto hacia la corrupción (entendida como el abandono a la satisfacción de los placeres sensibles, que distancia al alma del acceso a la verdad), como hacia la purificación del alma, se hallan en el propio alma, y el cuerpo sería solo un mero instrumento que puede servir para un fin como para el otro, no pudiendo decidir por él mismo ni sobre él mismo, mucho menos, sobre el alma, dado que, " siempre que estén en un mismo organismo alma y cuerpo, a uno le prescribe la naturaleza que sea esclavo y esté sometido, y a la otra mandar y ser dueña". (Fedro 80 a1-3)

Sobre lo mismo referirá Vegetti (1989) al sostener que:

Hay en el alma un principio propiamente humano, la razón, cuyos deseos específicos son el conocimiento y el saber: cumplirlos da lugar a la virtud de la sabiduría. Este principio de racionalidad es teórico y práctico a la vez: la sabiduría de la pequeña parte que gobierna el alma. (p. 178)

Con ello referiría justamente a la parte racional del alma, que es justamente la que se busca gobierne por sobre las demás y por sobre el cuerpo mismo. No es solo en lo referente al hado ${ }^{5}$ del alma, que encontramos un énfasis platónico, sino también en lo referente a la relación éntrelas acciones del hombre como ciudadano de la polis ${ }^{6}$, y este es uno de los puntos claramente señalados en el imperativo de la inquietud de sí,

\footnotetext{
${ }^{5}$ Destino.

${ }^{6}$ Hace referencia a ciudades- Estado griegas, comunidades políticas que se administraba a sí misma, constituida generalmente por una agrupación urbana y el territorio circundante.
} 
siendo la educación del alma, no solo importante para el alma misma, sino también en relación con su entorno político.

Es a todo esto, a lo que refiere el cuidado y la inquietud de sí mismo, a la educación del alma y consecuente buen gobierno de sí misma, ya que lo mismo desencadenaría en un buen gobierno de los demás. Recordemos que este punto es importante si tenemos en cuenta el contexto histórico y geográfico en el cual surgió toda la teoría platónica, que es el contexto de democracia, en el cual el hombre no es entendido sin la polis ni fuera de ella, prefiriendo el mismo Sócrates morir antes que renunciar y verse alejado de ella en la agonía del destierro.

“El objetivo general de la pedagogía platónica fue la formación del hombre de Estado. Para eso fundó la academia: para formar políticos y gobernantes" (Ballén Molina, 2010, p. 53). El hombre debe prepararse para ocuparse de sí y si la ciudad lo requiere, ocuparse de los asuntos de la misma, y esto no es un dato menor, ya que vemos que no refiere solo a la preparación para la muerte, como si liberarse del cuerpo fuese lo más urgente, sino que en todo momento se fomenta el buen uso del mismo, para un bien o fin mayor, que en este caso era la ciudad. La muerte llegaría tarde o temprano, y no era este hecho el que más importaba, sino más bien en cómo se hubiere aprovechado o no el tiempo transcurrido en el mundo sensible, en como el alma ejerció el gobierno sobre ella misma y sobre su propio cuerpo. Resulta vital para ello, que el alma corrija o modifique sus desvíos y sepa elegir lo que más le conviene para sí misma y para los demás, y para llevar a cabo esa modificación se vale del cuerpo, el alma no puede modificarse sola, se podría decir que, así como precisa de un cuerpo para satisfacer los deseos carnales o entregarse a los vicios y excesos; de igual manera precisa de un cuerpo para educarse a sí misma y llevar una vida virtuosa. "La buena educación es la que da al cuerpo y al alma toda la perfección y toda la belleza de que son capaces". (Ballén Molina, 2010, p. 37)

La vida virtuosa que se lleva a cabo luego la modificación y de tener acceso a la verdad, necesariamente deberá devenir luego en acciones, tener una vida conforme a la virtud o ser una persona virtuosa, no trata solo de conocer la virtud, sino de obrar conforme a ella, y no es solo el conocer el bien, sino el obrar conforme a él, lo que le 
permitirá al alma después de la muerte, un retorno afortunado al plano eidético añorado.

El doble anclaje entre Pedagogía y política, dejan entrever la importancia y correspondencia entre el saber para saber conducirse y la obligación ciudadana que con esto se encuentra implícita, dado que luego de ese alejamiento del mundo para purificarse y acceder a la verdad, es preciso llevarla a la práctica en la vida social de la polis. La educación prepara a los hombres para la virtud, y es esta virtud la que los hace deseosos y amantes de convertirse en buenos ciudadanos que saben gobernar y ser gobernados con justicia. "La educación es el más importante bien que los hombres pueden adquirir". (Ballén Molina, 2010, p. 37)

Si deseos y pasiones pertenecen al alma y no al cuerpo, resultarán en cierta medida homogéneos a la facultad racional, al principio del orden del alma, y serán al menos, potencialmente educables, gobernables, e incluso útiles para finalidades superiores; la parte irracional del alma no es tan impenetrable y hostil al gobierno de la razón como lo era una corporeidad intrínsecamente malvada. (Vegetti, 1989, p.175)

Al volver al alma la responsabilidad por los actos del cuerpo, al identificar como suyos los deseos y pasiones antes atribuidos al cuerpo, ya no percibiremos la vida restrictivamente como preparación para la muerte, ni su salvación como la liberación del cuerpo, sino que el foco fundamental se hallará ahora en la transformación del hombre y su propia vida a través de un gobierno justo del alma y la ciudad. Algo que ya podías apreciar y es fácil relacionar con la analogía expresada por Platón entre el alma tripartita y la constitución del Estado en la República, donde cada elemento del alma, se identifica con un conjunto de individuos que la componen. Así como la parte racional debe gobernar por sobre las otras partes del alma, de igual manera, quienes la posean en demasía, deben ser los encargados de gobernar el Estado ${ }^{7}$, ya que serían menos susceptibles de corrupción; de igual manera los que posean la valentía y se entrenen para ser la fuerza del Estado, es decir los guerreros, se asemejan a la parte irascible del alma, y como el caballo blanco y el cuerpo mismo, puede servir a los

\footnotetext{
${ }^{7}$ Aquí se está haciendo referencia a los Filósofos
} 
gobiernos más justos como a los tiranos. Por último, los que desempeñan trabajos manuales y de producción, se los relaciona con la parte concupiscible, porque son quienes menos dominio tienen por sobre sus pasiones. Esto solo refuerza la tesis de que el alma es quien realmente decide, el conflicto es interno, y según como lo resuelva será no solo su destino después de la muerte, sino también se decidirá el lugar que resulta conveniente que ocupe en la ciudad.

\section{Conclusión}

Durante mucho tiempo, diversos autores y fuentes filosóficas, a la hora de dar cuenta de la visión antropológica de Platón, la caracterizan como dualista y de oposición, dado que, las partes que lo compondrían, que son el cuerpo y el alma, se hallarían enfrentadas entre sí y serían de naturalezas ontológicamente contrapuestas, identificándose al alma con todo lo bueno y bello por pertenecer al plano eidético, y al cuerpo con lo viciado y corruptible por ser perteneciente al plano sensible. El alma por desgracia, cae precipitada de su patria y se ve atrapada en un cuerpo, del cual solo se verá liberada con la muerte, en él se ve expuesta a toda clase de desórdenes y olvida aquello que hubiere contemplado previamente en su patria, tarea suya es, por medio del ejercicio de la filosofía, recordarlo y vivir conforme a ello.

Ahora bien, el objetivo del trabajo era demostrar que esto no es así y liberar al cuerpo del yugo estigmatizador que lo ha venido acompañando durante tantos siglos, y que diferente a lo que se cree, el alma sería en realidad la verdadera responsable, tanto de su precipitación al plano sensible, como en lo referente a los males que en su pasar por el mismo cometiese. Si recordamos la composición tripartita del alma platónica, rápidamente podemos percatarnos de ello, ya que, en ella se halla presente tanto la parte racional que tiende y se deleita con la contemplación de las ideas, así como la parte concupiscible, que tendería en cambio a buscar un cuerpo para satisfacer sus deseos viciados. Pero solo esto no alcanza para redimir al cuerpo, y es en este punto donde los aportes de Foucault resultaron un gran aporte

Teniendo de referencia, todo lo expuesto en el desarrollo del trabajo, se concluye que es posible afirmar la hipótesis que sirvió de punto de partida para esta investigación, la cual consistía en señalar una función positiva del cuerpo que resultaba 
importante para llevar a cabo el mandato de la Inquietud de sí durante el período socrático platónico. Esta función rescatada por Foucault en el análisis de este período clásico expuesto en su Hermenéutica del Sujeto, rescata a la corporalidad platónica de la función carcelaria a la cual se hallaba restringida tradicionalmente.

Desde la visión foucaultiana y los aportes que nos deja su concepto de Inquietud de sí, como lo son la espiritualidad entendida en el contexto clásico y las tecnologías del yo, es posible rever la noción de cuerpo platónica y el rol que desempeñaría en torno al mandato de ocuparse de sí mismo y el papel fundamental que asume en el proceso de subjetivación que Foucault se propone con su investigación desentrañar, ya que, en este marco el sujeto debe modificarse para tener acceso a la verdad y esta modificación del alma se lleva a cabo por medio de las tecnologías del yo, mediada por el cuerpo, que es la herramienta de la cual se vale el alma para su fin. La corrección de los desvíos del alma, se realiza por medio del cuerpo, de igual forma que su corrupción.

Este trabajo resulta de gran aporte al campo, en la medida en que nos ofrece una nueva mirada respecto a la corporalidad platónica, sino también del alma, posibilitando a la vez encontrarnos con nuevas formas de relacionarnos con el cuerpo y si se quiere de volver a responsabilizarnos sobre el mismo. Hay muchas revisiones y vueltas hasta hoy sobre los autores de la filosofía clásica, y muchos que se detienen a reflexionar sobre aspectos antropológicos o dualistas, éticos o políticos; pero muy pocos se detienen a ver el papel que juega la corporalidad, el rol importante que desempeña. Parece que hasta hoy subsisten resabios de esa idea tradicional que separa y enfrenta las cuestiones corporales de las racionales, como si se tratase de dos planos diferentes de la realidad sin otro punto de conexión más que el de coexistir en un lugar y tiempo determinados, y aun en las mismas religiones que nos acompañan hasta hoy, parece tener un lugar de estorbo que no nos permite llegar a cosas más celestiales y trascendentales o al menos nos limitaría en el proceso. Hasta hoy, seguimos buscando un chivo expiatorio donde depositar el origen o la culpa de nuestros males, quitando la responsabilidad que tenemos como actores de los mismos. 


\section{Bibliografía}

Ballén Molina, R. (julio de 2010). La Pedagogía en los Diálogos de Platón. Diálogos de Saberes. P. 35-54.

Foucault, M. (2015). La Hermenéutica de Sujeto. Trad. Horacio Pons. México: Fondo de Cultura Económica.

Foucault, M. (1991). Tecnologías del yo. Trad. Mercedes Allende Salazar. Barcelona, España: Paidós.

Hadot, P. (1998). ¿Qué es la Filosofía Antigua?. Trad. Eliane Cazanave Tapie Isoard. México: Fondo de Cultura Económica.

Hadot, P. (2006). Ejercicios Espirituales y Filosofía Antigua. Trad. Javier Palacio. España: Siruela.

Jaeger, W. (1980). Paideia: Los ideales de la cultura griega. México: Fondo de Cultura Económica.

Marrou, H. (1971). Historia de la Educación en la Grecia Antigua. Trad. Yago Barja de Quiroga. Madrid, España: Akal.

Platón. (1988). Diálogos III: Fedón, Banquete y Fedro. Trad. García Gual. Madrid, España: Gredos.

Platón. (1988). República. Trad. Conrado Eggers Lan. Madrid, España: Gredos.

Reale, G. y Antiseri, D. (1988). Historia del Pensamiento filosófico y científico I: Antigüedad y Edad Media. Barcelona, España: Herder.

Vegetti, M. (1989). La ética de los antiguos. Madrid, España: Síntesis. 